\title{
Complex population genetic and demographic history of the Salangid, Neosalanx taihuensis, based on cytochrome b sequences Liang Zhao ${ }^{1,3,4}$, Jie Zhang ${ }^{2}$, Zhijin Liu' ${ }^{1}$, Stephan M Funk ${ }^{5}$, Fuwen Wei ${ }^{1}$, Muqi $\mathrm{Xu}^{1}$ and Ming $\mathrm{Li}^{* 1}$
}

Address: ${ }^{1}$ Key laboratory of Animal Ecology and Conservation Biology, Institute of Zoology, Chinese Academy of Sciences, Chaoyang, Beijing 100101, PR China, ${ }^{2}$ Key laboratory of zoological Evolution and Systematics, Institute of Zoology, Chinese Academy of Sciences, Chaoyang, Beijing 100101, PR China, ${ }^{3}$ Faculty of biology, Suzhou University, Suzhou, Anhui 234000, PR China, ${ }^{4}$ Graduate School of the Chinese Academy of Sciences, Beijing 100039, PR China and ${ }^{5}$ Nature Heritage Ltd, London, UK

Email: Liang Zhao - zhaoliang@ioz.ac.cn; Jie Zhang - zhangjie@ioz.ac.cn; Zhijin Liu - liuzj@ioz.ac.cn; Stephan M Funk - zorrochilote@gmail.com; Fuwen Wei - weifw@ioz.ac.cn; Muqi Xu - xumq@ioz.ac.cn; Ming Li* - lim@ioz.ac.cn

* Corresponding author

Published: 14 July 2008

BMC Evolutionary Biology 2008, 8:201 doi:10.1 |86/I47|-2|48-8-201
Received: 2 February 2008

Accepted: 14 July 2008

This article is available from: http://www.biomedcentral.com/I47I-2| 48/8/20I

(C) 2008 Zhao et al; licensee BioMed Central Ltd.

This is an Open Access article distributed under the terms of the Creative Commons Attribution License (http://creativecommons.org/licenses/by/2.0), which permits unrestricted use, distribution, and reproduction in any medium, provided the original work is properly cited.

\begin{abstract}
Background: The Salangid icefish Neosalanx taihuensis (Salangidae) is an economically important fish, which is endemic to China, restricted to large freshwater systems (e.g. lakes, large rivers and estuaries) and typically exhibit low vagility. The continuous distribution ranges from the temperate region of the Huai and Yellow River basins to the subtropical region of the Pearl River basin. This wide ranging distribution makes the species an ideal model for the study of palaeoclimatic effects on population genetic structure and phylogeography. Here, we aim to analyze population genetic differentiation within and between river basins and demographic history in order to understand how this species responded to severe climatic oscillations, decline of the sea levels during the Pleistocene ice ages and tectonic activity.
\end{abstract}

Results: We obtained the complete mtDNA cytochrome $b$ sequences (I I I l bp) of 354 individuals from 13 populations in the Pearl River, the Yangze River and the Huai River basin. Thirty-six haplotypes were detected. Haplotype frequency distributions were strongly skewed, with most haplotypes $(n=24)$ represented only in single samples each and thus restricted to a single population. The most common haplotype $(\mathrm{H} 36)$ was found in $49.15 \%$ of all individuals. Analysis of molecular variance (AMOVA) revealed a random pattern in the distribution of genetic diversity, which is inconsistent with contemporary hydrological structure. Significant levels of genetic subdivision were detected among populations within basins rather than between the three basins. Demographic analysis revealed that the population size in the Pearl River basin has remained relatively constant whereas the populations in the Yangze River and the Huai River basins expanded about $22 \mathrm{I}$ and $190 \mathrm{kyr}$ ago, respectively, with the majority of mutations occurring after the last glacial maximum (LGM).

Conclusion: The observed complex genetic pattern of $\mathrm{N}$. taihuensis is coherent with a scenario of multiple unrelated founding events by long-distance colonization and dispersal combined with contiguous population expansion and locally restricted gene flow. We also found that this species was likely severely impacted by past glaciations. More favourable climate and the formation of large suitable habitations together facilitated population expansion after the late Quaternary (especially the LGM). We proposed that all populations should be managed and conserved separately, especially for habitat protection. 


\section{Background}

Population genetic structure is dependent on the interaction of the biology of a species and the environment in which it resides. Marine organisms generally show low levels of genetic differentiation over large geographic distances $[1,2]$. In open marine systems it is evident that higher dispersal potential during planktonic egg, larval, or adult stages coupled with the absence of physical barriers to movement seems to greatly facilitate extensive gene flow among populations of organisms [3,4]. However, populations of freshwater fish species from different basins often show significant genetic differentiation resulting from isolation, while populations within a basin often show no or low levels of genetic differentiation [59]. There is evidence that for some species instream barriers can restrict gene flow and induce high levels of genetic differentiation between populations [10,11]. Even in the absence of restricted gene flow, multiple unrelated founding events could also shape the same pattern of population genetic structure [4].

Due to periodic climatic oscillations during the Pleistocene, range contractions, range expansions and changes in interconnectivity within and between drainages during the periodic climatic oscillations of the Pleistocene have greatly influenced the distribution of many fish species, have significantly altered the amount and distribution of intraspecific genetic variation in many species and have remodelled the population structures of temperate fish faunas $[1,5]$. The major climatic oscillations occurred during the past $800 \mathrm{kyr}$ (with a $100 \mathrm{kyr}$ dominant cycle), and the last glacial maximum (LGM) occurred about $18 \mathrm{kyr}$ ago with a decline of the sea levels of about 120-140 m [12]. Each of the severe climatic shifts and the change in the sea levels could have produced great changes in the freshwater fish species' geographical distribution and abundance $[1,5,13,14]$. The legacy of these changes in the phylogeographic distribution of genetic diversity has been traced in several species $[5,15,16]$. In Cyprinids, it has been shown that glacial, interglacial and postglacial oscillations have resulted in major changes of distributions and have shaped current distributions by changes of river courses and river confluences in response to falling sea levels $[13,14]$.

The Family Salangidae, which is classified as Protacanthopterygii, Order Osmeriformes, Suborder Osmeroidei $[17,18]$, comprises six genera and approximately 17 species $[19,20]$. The Salangid, Neosalanx taihuensis, is one of the most economically important species in this Family. This species is endemic to China and is restricted to large bodied freshwater systems such as inland lakes, out-flowing rivers and estuaries, covering a continuous distribution from the temperate (Yellow River basin) to the subtropical zone (Pearl River basin) [21]. Also, this spe- cies exhibits annualism poor swimming ability and has some neotenic features such as transparent miniaturized bodies, cartilaginous endoskeletons, and notochords $[20,22]$. The combination of relative large spatial distribution encompassing discrete drainages in tropical and subtropical regions and the low vagility constitutes a good model system to study the palaeoclimatic effects on population genetic structure and phylogeography of freshwater [23]. In recent years, because of water pollution, overfishing and habitat destruction, the population of $N$. taihuensis has undergone the lost of appropriate habitat and the decrease in population size [24,25]. In order to protect the resource of $N$. taihuensis, the habitat detection has to be implemented immediately, and the study on the $N$. taihuensis population structure and its phylogeoraphic pattern should be enhanced since the failure to detect population units will lead to local overfishing and ultimately to severe declines [26]. The Salangidae family has been studied for more than 200 years, but most of studies have focused on taxonomy [27,28], biology [29], and molecular phylogeny [30]. Previous studies in China have shown that in two unrelated species, Opsariichthys bidens (Teleostei, Cyprinidae) and Brachymystax lenok Pallas (Salmoninae, Salmonidae), both had genetic patterns coinciding with contemporary drainage structure $[8,9]$, but the related study on $N$. taihuensis is not conducted till now.

The basins of Yangtze River, Huai River and Pearl River, in which $N$. taihuensis mainly distributes, are important river systems in China. Although a strong uplifting of the Tibetan plateau occurred during the Pleistocene in southwest China [31], there is no evidence to indicate that large-scale river rearrangement occurred after the Pliocene in the mid-lower reaches of these basins [32]. The Yangze River and the Huai River basin are connected by the Peking Hangzhou Canal, while there are no connection between Pearl River basin and the others[33]. Given the intolerance of the $N$. taihuensis to waters with some salt content, members of freshwater fish division cannot disperse by river connections [34]. Therefore, we expect vicariance among basins might play an important role in shaping population genetic structure of $N$. taihuensis. In addition, the glaciations during the Pleistocene, especially the last glacial maximum (LGM) with sea levels lowered (120-140 m below present sea level), should have severely affected the genetic structure of this species. In order to detect the population structure and phylogeographic pattern of $N$. taihuensis at large geographical scales, samples of $N$. taihuensis were collected from 13 populations among the Pearl River basin, the Yangtze River basin, and the Huai River basin (Figure. 1). The complete mtDNA cytochrome $b$ gene $(c y t b)$ sequence was used to analyze population genetic differentiation of this species, population dynamics and demographic history, and to show how the glaciations influenced the phyloge- 


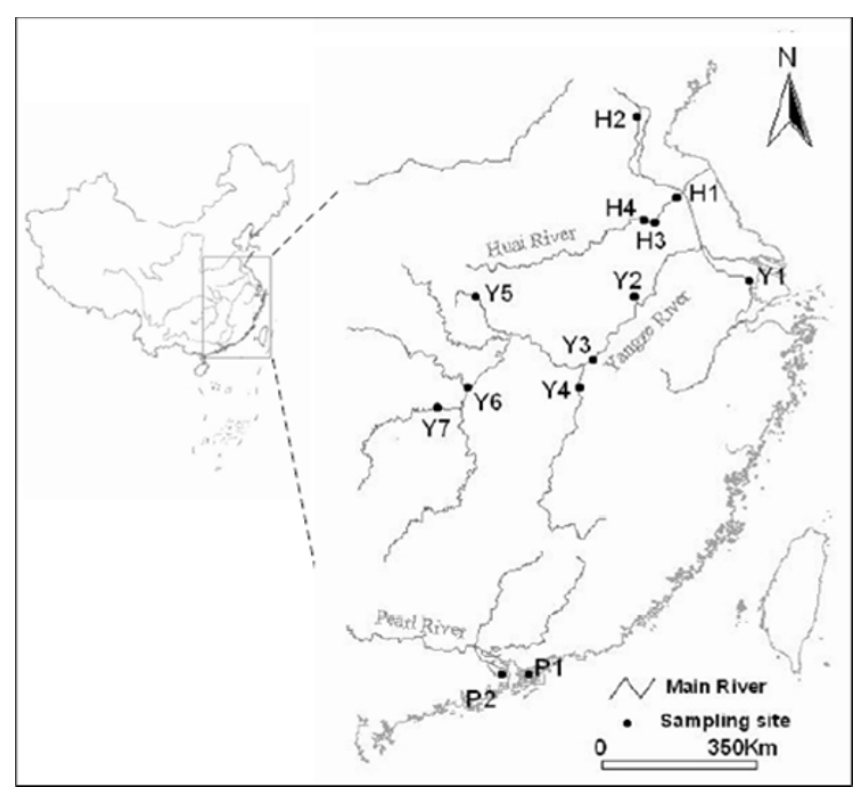

Figure I

Map of the distribution of $N$. taihuensis and the sampling locations for this study.

ographic patterns of freshwater fish, and how this species responded to the severe climatic oscillations and decline of the sea levels during the Pleistocene ice ages.

\section{Results}

\section{Sequence Variation and Genetic Diversity}

For $1141 \mathrm{bp}$ of the complete $c y t b$ gene analyzed in 354 individuals, there were 38 variable nucleotide sites, and no insertions or deletions in any of the sequences. The average nucleotide composition for all individuals was highest for $\mathrm{C}(0.334)$, followed by $\mathrm{T}(0.277)$, A (0.214), and $G(0.175)$. Nucleotide composition showed an anti$\mathrm{G}$ bias $(\mathrm{G}=17.5 \%)$, which is characteristic for the mitochondrial genome [35]. Since there were no stop codons when the $c y t b$ sequence was translated into amino acid sequences, and based on the criteria of Zhang \& Hewitt [36], we found no evidence for nuclear mitochondrial pseudogenes (Numts) in our PCR sequences. Linkage disequilibrium (LD) test and selective neutrality test were implemented for $c y t b$ sequences in $N$. taihuensis, which indicated that there was no signs of recombination $(P=$ 0.925 ) and the neutral hypothesis (no selection) could not be rejected $(P=0.172)$ for these $c y t b$ sequences. Thus, the $c y t b$ was suitable marker for analyzing the evolutionary history of this species.

Thirty-six different haplotypes were identified in the 354 samples analyzed (Table 1 and Table 2). The number of haplotypes ranged from 5 to 25 for each basin. The populations with the greatest number of haplotypes were the Taihu lake population (8) and Chaohu lake population (8) in Yangze River basin, and the Hongzehu lake population (8) in Huai River basin. The haplotype frequency distribution was strongly skewed, with the vast majority of haplotypes found only once (24 out of 36 ) and restricted to a single population. H36, the most common haplotype found in 12 sampled populations with the exception of

Table I: Descriptive statistics of $N$. taihuensis phylogroups based on mitochondrial cytb sequence data

\begin{tabular}{|c|c|c|c|c|c|c|c|}
\hline Population & location & $\mathbf{N}$ & $H$ & $\boldsymbol{h}$ & $S$ & k & $\pi$ \\
\hline Pearl River basin & & 44 & 5 & $0.622 \pm 0.064$ & 8 & 1.261 & $0.0011 \pm 0.0003$ \\
\hline PI & Luofu River & 31 & 5 & $0.443 \pm 0.105$ & 8 & 1.213 & $0.0011 \pm 0.0004$ \\
\hline P2 & Pearl River & 13 & 3 & $0.513 \pm 0.144$ & 2 & 0.744 & $0.0007 \pm 0.0002$ \\
\hline Yangze River basin & & 197 & 25 & $0.781 \pm 0.017$ & 28 & 3.080 & $0.0027 \pm 0.0001$ \\
\hline YI & Taihu lake & 31 & 8 & $0.798 \pm 0.039$ & 11 & 3.174 & $0.0028 \pm 0.0002$ \\
\hline Y2 & Chaohu lake & 25 & 8 & $0.763 \pm 0.068$ & 10 & 1.380 & $0.0012 \pm 0.0003$ \\
\hline Y3 & Bohu lake & 29 & 5 & $0.650 \pm 0.078$ & 10 & 2.606 & $0.0023 \pm 0.0004$ \\
\hline Y4 & Poyanghu lake & 22 & 5 & $0.407 \pm 0.128$ & 8 & 1.589 & $0.0014 \pm 0.0005$ \\
\hline Y5 & Dongtinghu lake & 27 & 5 & $0.393 \pm 0.114$ & 6 & 0.576 & $0.0005 \pm 0.0002$ \\
\hline Y6 & Tianrezhou & 34 & 5 & $0.570 \pm 0.078$ & 8 & 1.210 & $0.0011 \pm 0.0003$ \\
\hline Y7 & Xujiahe Reservoir & 29 & 2 & $0.296 \pm 0.093$ & 3 & 0.887 & $0.0008 \pm 0.0002$ \\
\hline Huai River basin & & 113 & 15 & $0.464 \pm 0.057$ & 18 & 1.110 & $0.0010 \pm 0.0002$ \\
\hline $\mathrm{HI}$ & Hongzehu lake & 26 & 8 & $0.686 \pm 0.088$ & 11 & 2.348 & $0.0021 \pm 0.0003$ \\
\hline $\mathrm{H} 2$ & Weishanhu lake & 31 & 4 & $0.553 \pm 0.060$ & 6 & 0.796 & $0.0007 \pm 0.0002$ \\
\hline $\mathrm{H} 3$ & Wabuhu lake & 30 & 2 & $0.067 \pm 0.061$ & I & 0.067 & $0.000 \mathrm{I} \pm 0.000 \mathrm{I}$ \\
\hline $\mathrm{H} 4$ & Chengdonghu lake & 26 & 6 & $0.354 \pm 0.119$ & 9 & 0.834 & $0.0007 \pm 0.0003$ \\
\hline Entire region (all samples) & & 354 & 36 & $0.713 \pm 0.022$ & 38 & 2.528 & $0.0022 \pm 0.0001$ \\
\hline
\end{tabular}

Note: $N$, number of individuals; $H$, number of haplotypes; $S$, number of segregating sites; $h$, gene diversity ( \pm Standard Deviation); $k$, mean pair-wise nucleotide; $\pi$, nucleotide diversity ( \pm Standard Deviation) 
Table 2: Summary of mtDNA cytb region haplotype distributions

\begin{tabular}{|c|c|c|c|c|c|c|c|c|c|c|c|c|c|c|}
\hline \multirow[t]{2}{*}{ Haplotypeslpopulations } & \multicolumn{2}{|c|}{ Pearl River basin } & \multicolumn{7}{|c|}{ Yangze River basin } & \multicolumn{4}{|c|}{ Huai River basin } & \multirow[t]{2}{*}{ Tota } \\
\hline & $\mathbf{P I}$ & $\mathbf{P 2}$ & $\mathbf{Y I}$ & $\mathbf{Y 2}$ & Y3 & Y4 & Y5 & Y6 & Y7 & $\mathbf{H I}$ & $\mathrm{H} 2$ & H3 & H4 & \\
\hline HOI & I & & & & & & & & & & & & & 1 \\
\hline HO2 & 3 & & & & & & & & & & & & & 3 \\
\hline H03 & & & 1 & & & & & & & & & & & 1 \\
\hline H04 & & & 1 & & & & & & & & & & & 1 \\
\hline H05 & & & 1 & & & & & & & & & & & 1 \\
\hline H06 & & & I & & & & & & & & & & & 1 \\
\hline H07 & & & 2 & & & & & & & & & & & 2 \\
\hline H08 & & & & I & & & & & & & & & & 1 \\
\hline H09 & & & & I & & & & & & & & & & 1 \\
\hline HIO & & & & 4 & & & & & & & & & & 4 \\
\hline HII & & & & 1 & & & & & & & & & & 1 \\
\hline HI2 & & & & & 2 & & & & & & & & & 2 \\
\hline $\mathrm{HI3}$ & & & & & 1 & & & & & & & & & 1 \\
\hline HI4 & & & & & & 1 & & & & & & & & 1 \\
\hline HI5 & & & & & & 1 & & & & & & & & 1 \\
\hline HI6 & & & & & & & 1 & & & & & & & 1 \\
\hline HI7 & & & & & & & 3 & & & & & & & 3 \\
\hline HI8 & & & & & & & 1 & & & & & & & 1 \\
\hline HI9 & & & & & & & 1 & & & & & & & 1 \\
\hline $\mathrm{H} 2 \mathrm{O}$ & & & & & & & & 1 & & & & & & 1 \\
\hline H2I & & & & & & & & 1 & & & & & & 1 \\
\hline $\mathrm{H} 22$ & & & & & & & & & & I & & & & 1 \\
\hline $\mathrm{H} 23$ & & & & 1 & & & & & & 1 & & & & 2 \\
\hline H24 & & & & & & & & & & 1 & & & & 1 \\
\hline $\mathrm{H} 25$ & & & & & & & & & & 2 & & & & 2 \\
\hline $\mathrm{H} 26$ & & & & & & & & & & 1 & & & & 1 \\
\hline $\mathrm{H} 27$ & & & 9 & & 16 & & & 3 & 24 & 5 & 1 & & & 58 \\
\hline $\mathrm{H} 28$ & & & & & & & & & & & 1 & & & I \\
\hline H29 & 1 & 9 & & & & 2 & & 8 & & & II & & & 31 \\
\hline H30 & & & & & & & & & & & & 1 & & 1 \\
\hline H3 I & & & & & & & & & & & & & 1 & I \\
\hline H32 & & & & & & & & & & & & & 1 & 1 \\
\hline H33 & & & 7 & 1 & 6 & 17 & & & 5 & I & & & 1 & 38 \\
\hline H34 & & & & & & & & & & & & & 1 & I \\
\hline H35 & 3 & 2 & & 5 & & & & & & & & & 1 & $\mathrm{II}$ \\
\hline H36 & 23 & 2 & 9 & II & 4 & 1 & 21 & 21 & & 14 & 18 & 29 & 21 & 174 \\
\hline Sample Number & 31 & 13 & 31 & 25 & 29 & 22 & 27 & 34 & 29 & 26 & 31 & 30 & 26 & 354 \\
\hline
\end{tabular}

the Xujiahe reservoir population, occupied $49.15 \%$ of all individuals among all populations $(56.82 \%$ for the Pearl River basin, 37.43\% for the Yangtze River basin, 72.57\% for the Huai River basin). Other common haplotypes found in all three basins were $\mathrm{H} 27, \mathrm{H} 33$ and $\mathrm{H} 25$, with $16.38 \%, 10.73 \%$ and $3.11 \%$ of all individuals, respectively (Table 2).

Diversity indices (average \pm standard deviation), $h$ and $\pi$, are summarized in Table 1 . The total of $h$ was $0.713 \pm$ 0.022 ranging from $0.473 \pm 0.057$ to $0.781 \pm 0.017$, and $\pi$ was $0.0022 \pm 0.0001$ ranging from $0.0010 \pm 0.0002$ to $0.0027 \pm 0.0001$ among there basins. There are no evidences that heterogeneous levels of genetic variability were produced by unequal sample size for each population through Pearson's correlation test between diversity indices and sample size $(\mathrm{r}=0.082$ and $P=0.790$ for numbers of haplotypes, $\mathrm{r}=-0.02$ and $P=0.996$ for haplotype diversity, and $\mathrm{r}=0.141$ and $P=0.645$ for nucleotide diversity, respectively). These results showed a medium/high haplotype diversity and a low nucleotide diversity, and that the genetic diversity for three near-coastal populations (the Taihu lake population and the Chaohu lake population within the Yangze River basin, and the Hongzehu lake population within the Huai River basin) were higher than others (Table 1).

\section{Population Structure and Phylogeography}

Unrooted ML tree revealed that there were no distinct haplotype groups with high bootstrap support (<60\%) and there was no geographical structure among haplotypes (Figure. 2), which was supported by network analy- 


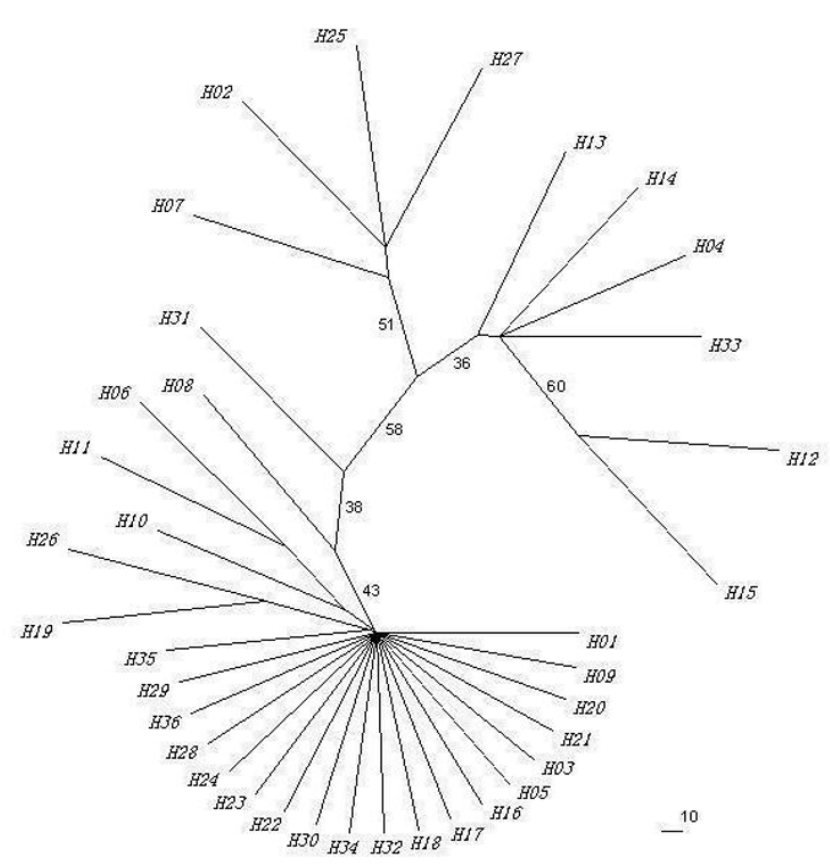

Figure 2

Unrooted Maximum-likelihood tree for all 36 haplotypes of $\boldsymbol{N}$. taihuensis. Labels are haplotype identification numbers shown in Table 2. Values indicate bootstrap support for each node based on maximum likelihood inference.

sis (Figure. 3). In this study, only a few missing haplotypes were detected, which indicated that we gathered enough samples (both numbers of individuals and locations within the distribution) for phylogeographical analysis. Each haplotype was connected with others by 1 to 3 mutational steps, suggesting that there was no deep branching among halotypes for this species. In network, H36 yielded the highest outgroup weight $(0.2941)$ followed by $\mathrm{H} 27$ (0.0588), H33 (0.0588), and H35 (0.0441), indicating $\mathrm{H} 36$ was the most probable ancestral haplotype [37]. In fact, the high frequency of shared haplotypes (i.e., H36, H27, H33, H29) were found among all basins, which produced a pattern of population relationships associated with the ancestry of the haplotypes found within each population rather than with the hydrological network (Figure. 2, Figure. 3). Thus, we suggested that there was no obvious phylogeographic pattern within $N$. taihuensis.

Pair-wise comparisons $\Phi_{S T}$ test among 13 populations showed that the differences among the most of populations were irrelevant to their distributions (Table 3). AMOVA analysis revealed that there were significant subdivisions within and among populations of $N$. taihuensis, but no significant genetic variance was found among basins, with only $8.43 \%$ of the genetic variance was found among basins (Table 4), which provided evidences that
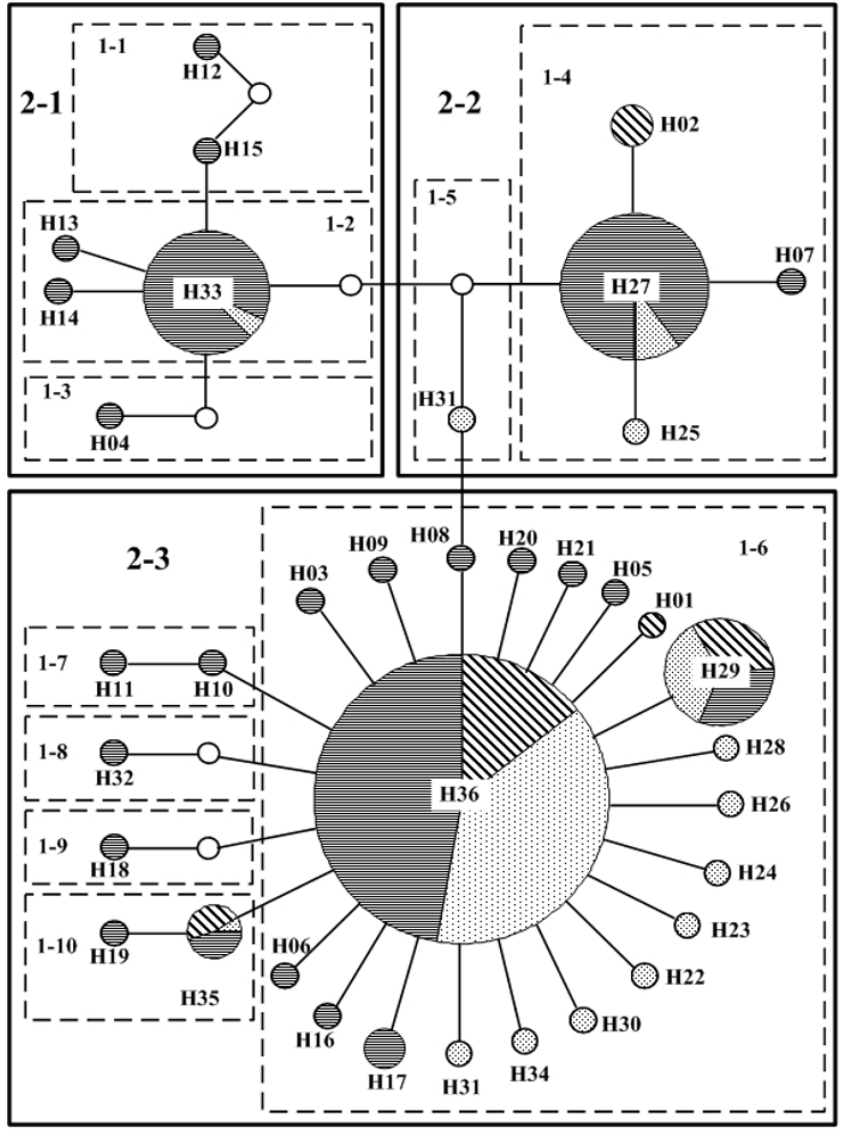
Q [Pearl River Basin]
[Huai River Basin]
[Yangze River Basin]
[Missing Haplotype]

Figure 3

Minimum spanning network based on Templeton et al. $(1987,1993)$ statistical parsimony. Nodes contain the haplotype number and are proportional to the haplotype frequency. White nodes indicate undetected intermediate haplotype states separated by one mutational step. Boxes indicate one-step to two-step nesting levels for the nested clade analysis in NCA.

the high level of population structure was not related to the hydrological pattern. The Mantel test indicated no significant relationship between $\Phi$ st/(1- $\Phi$ st) and geographic distance among populations, with $P=0.59$ for all 13 populations among basins, $P=0.82$ for 7 populations within Yangze River basin and $P=0.19$ for 4 populations within Huai River basin, respectively.

The NCA analysis (see additional file 1) provided some historical information for the pattern of genetic differentiation for $N$. taihuensis. The widespread clade 1-6 with significantly small $D c$ and large $D n$, were indicative longdistance colonization (and/or past fragmentation). Clade $1-2$, clade $1-4$, and two second cladistic levels of clade 2- 
Table 3: Pairwise $\Phi_{S T}$ among N. taihuensis populations

\begin{tabular}{|c|c|c|c|c|c|c|c|c|c|c|c|c|c|}
\hline \multirow[t]{2}{*}{ populations } & \multicolumn{2}{|c|}{ Pearl River basin } & \multicolumn{7}{|c|}{ Yangze River basin } & \multicolumn{4}{|c|}{ Huai River basin } \\
\hline & $P_{1}$ & $P_{2}$ & $Y_{1}$ & $Y_{2}$ & $Y_{3}$ & $Y_{4}$ & $Y_{5}$ & $Y_{6}$ & $Y_{7}$ & $\mathrm{H}_{\mathrm{I}}$ & $\mathrm{H}_{2}$ & $\mathrm{H}_{3}$ & $\mathrm{H}_{4}$ \\
\hline$P_{1}$ & & 61.9 & 1335.0 & II55.4 & 953.7 & 808.1 & 808.5 & 869.7 & 1081.9 & 1429.4 & 1532.0 & 1221.0 & 1193.8 \\
\hline $\mathrm{P}_{2}$ & $0.3146^{*}$ & & 1360.6 & 1176.6 & 974.9 & 829.3 & 777.5 & 838.7 & 1074.7 & 1450.6 & 1553.2 & 1215.0 & 1242.2 \\
\hline$Y_{1}$ & $0.308 I^{*}$ & $0.4161 *$ & & 331.0 & 471.7 & 619.1 & 983.8 & 822.0 & 658.2 & 278.9 & 604.6 & 380.5 & 423.6 \\
\hline$Y_{2}$ & 0.0309 & $0.2873^{*}$ & $0.3292 *$ & & 194.9 & 344.0 & 645.9 & 484.1 & 328.8 & 261.2 & 462.1 & 108.8 & 125.1 \\
\hline$Y_{3}^{2}$ & $0.5349 *$ & $0.6046^{*}$ & 0.0511 & $0.5442 *$ & & 142.3 & 513.0 & 351.1 & 333.4 & 470.5 & 600.8 & 268.1 & 259.2 \\
\hline$Y_{4}^{3}$ & $0.7094 *$ & $0.7592 *$ & $0.279 I^{*}$ & $0.6947^{*}$ & $0.2818^{*}$ & & 413.4 & 291.8 & 389.6 & 618.0 & 720.6 & 409.6 & 382.4 \\
\hline$Y_{5}^{\top}$ & 0.0420 & $0.4304^{*}$ & $0.4070^{*}$ & $0.0633^{*}$ & $0.624 I *$ & $0.7834^{*}$ & & 156.4 & 419.6 & 885.8 & 951.7 & 658.0 & 626.7 \\
\hline$Y_{6}$ & 0.0340 & 0.1611 & $0.3255^{*}$ & $0.0817^{*}$ & $0.545 I^{*}$ & $0.7073^{*}$ & $0.0768^{*}$ & & 271.5 & 723.9 & 789.8 & 496.1 & 464.8 \\
\hline$Y_{7}^{0}$ & $0.7476^{*}$ & $0.8327^{*}$ & $0.2340^{*}$ & $0.7560^{*}$ & 0.0675 & $0.583 I^{*}$ & $0.8353^{*}$ & $0.7463^{*}$ & & 560.0 & 500.8 & 333.8 & 276.9 \\
\hline $\mathrm{H}_{1}$ & 0.0753 & 0.2961 & 0.0996 & 0.1331 & $0.3043^{*}$ & 0.5349* & $0.1874 *$ & 0.1016 & $0.5247^{*}$ & & 316.1 & 224.9 & 291.3 \\
\hline $\mathrm{H}_{2}$ & $0.1196 *$ & 0.1137 & $0.4003 *$ & $0.1459 *$ & $0.6103^{*}$ & $0.7622 *$ & $0.154 I^{*}$ & -0.0008 & $0.8109 *$ & $0.1988^{*}$ & & 351.8 & 338.1 \\
\hline $\mathrm{H}_{3}$ & 0.0582 & $0.6489 *$ & $0.4499 *$ & $0.1012^{*}$ & $0.6725^{*}$ & $0.8403^{*}$ & 0.0300 & $0.0927^{*}$ & $0.8882^{*}$ & $0.2283^{*}$ & $0.2123^{*}$ & & 53.6 \\
\hline $\mathrm{H}_{4}$ & -0.0008 & $0.3672 *$ & $0.3368^{*}$ & 0.0295 & $0.5673 *$ & 0.7339* & 0.0169 & 0.0383 & $0.794 I^{*}$ & 0.1157 & $0.1212 *$ & 0.0190 & \\
\hline
\end{tabular}

$\Phi_{S T}$ values are reported below, and the river distances $(\mathrm{km})$ between populations above, the diagonal. Asterisks indicate significant values after Bonferroni correction.

1, clade 2-2 indicated restricted gene flow with isolation by distance, and the overall picture of NCA indicated historical contiguous range expansion.

\section{Demographic Analysis}

An examination of demographic histories revealed the marked differences among the basins under study (Table 5, Figure 4, Figure 5). The skyline plots [38,39] of $N$. taihuensis in the entire region and the Yangze River basin showed a sudden stepwise expansion. Fu's Fs [40], RamosOnsins and Rozas's $R_{2}[41]$ tests for the entire region and Fu's Fs test for Yangze River basin were statistically significant negative, supported this point. Although both Fs and $R_{2}$ tests could not effectively tell the causes of bottleneck or expansion, Fu and Li's $D^{*}$ [42] tests were not significant $(P>0.05)$ for these populations, suggesting that there were no historical reduction in effective population size in these regions. The mtDNA mismatch analyses for the entire region and the Yangze River basin showed bimodal profile which might result from constant population size among an old population or an admixture population (Figure 5). However, the mismatch distribution goodness of fit test (Table 5) was not significant, which indicated that there were no severe departure from the estimated demographic model. Moreover, the results of the coales- cent based analysis using FLUCTUATE1.4 [43] showed high growth rate, $g=2648.97 \pm 556.26$ for the entire region and $g=3268.21 \pm 873.30$ for the Yangze River basin, providing powerful evidences of population expansion in these regions. In contrast to that of the entire region and the Yangze River basin, the skyline plot for Huai River basin provided evidence that the exponential growth model fitted the population demographic fluctuation well (Figure 4). Significant Fu's Fs $(P<0.05)$ and Ramos-Onsins and Rozas's $R_{2}(P<0.05)$ test, as well as high growth rate $(g=2083.14 \pm 529.35)$ confirmed population growth in Huai River basin, which was also supported by the test of Hri $(P>0.95)$, although the bimodal mismatch distribution (Figure. 5) and significance of SSD $(P<0.05)$ indicated a poor fit for the stepwise growth model (Table 5). For the Pearl River basin, the bimodal mismatch distribution (Figure. 5) and significance of $S S D$ $(P<0.05)$ values indicated a relative constant population size. Fu and Li's $D^{*}$ test, Fu's Fs and $R_{2}$ test for Pearl River basin were not significant, which also rejected population expansion/bottleneck model (Table 5). In addition, a relative constant population size was confirmed by a relative low growth rate $(\mathrm{g}=-309.64 \pm 955.56)$ with the approximate $95 \%$ confidence interval of $g$ included zero in this region.

Table 4: The results of AMOVA for $N$. taihuensis mtDNA cytb estimated using $\Phi$-statistics

\begin{tabular}{cccccc}
\hline Source of variation & d.f. & Sum of squares & Variance components & $\%$ variation & $\Phi$ statistics (P-value) \\
\hline Among basins & 2 & 55.055 & 0.1143 & 8.43 & $\Phi_{\mathrm{CT}}=0.0843$ \\
Among populations within basins & 10 & 158.543 & 0.5593 & 41.26 & $\Phi_{\mathrm{SC}}=0.4506^{* *}$ \\
Within populations & 341 & 232.530 & 0.6819 & 50.31 & $\Phi_{\mathrm{ST}}=0.4970^{* *}$ \\
$\quad$ Total & 353 & 446.127 & 1.3555 & & \\
\hline
\end{tabular}

$(* P<0.05, * * P<0.01)$ 
Table 5: Statistical test for neutrality, mismatch analysis and the estimate of demographic parameters for $N$. taihuensis based on mitochondrial cytb sequence data

\begin{tabular}{ccccc}
\hline & Entire region & Pearl River basin & Yangze River basin & Huai River basin \\
\hline Hri $(\boldsymbol{P}$ value $)$ & $0.0675(0.4687)$ & $0.1418(0.0608)$ & $0.0518(0.2609)$ & $0.1446(0.999)$ \\
SSD $(\boldsymbol{P}$ value $)$ & $0.0388(0.3002)$ & $0.0239(0.0411) *$ & $0.0336(0.1401)$ & $0.0131(0.001)^{* *}$ \\
$D^{*}(\boldsymbol{P}$ value $)$ & $-0.1047(0.5730)$ & $-0.1036(0.5910)$ & $-0.0991(0.5590)$ & $-0.1276(0.5060)$ \\
$R_{2}(\boldsymbol{P}$ value $)$ & $0.0726(0.0160)^{*}$ & $0.1177(0.1794)$ & $0.0825(0.1430)$ & $0.0859(0.0020)^{* *}$ \\
Fs $(\boldsymbol{P}$ value $)$ & $-18.9472(0.0002)^{* *}$ & $0.4106(0.6238)$ & $-7.4204(0.0279)^{*}$ & $-9.2412(0.0019) * *$ \\
$g \pm 3 *$ SD & $2648.97 \pm 556.26$ & $-309.64 \pm 955.56$ & $3268.21 \pm 873.30$ & $2083.14 \pm 529.35$ \\
$\tau(\mathbf{9 0} \% \mathbf{C l})$ & $5.602(0.619-10.090)$ & & $5.064(1.334-8.439)$ & 190.0 \\
TMRCA $(\mathbf{k y r})$ & & 73.53 & &
\end{tabular}

$(* P<0.05$, ** $P<0.01)$

According to the tau value $(\tau)$ and the mutation rates for the cyt $b$ gene $(1 \%$ per nucleotide per generation per million years), the estimated expansion time was found to be $245.5 \mathrm{kyr}$ ago for the entire region and $221.9 \mathrm{kyr}$ ago for the Yangze River basin. Using the coalescent method, an estimate of TMRCA was $190.0 \mathrm{kyr}$ for this species in the Huai River basin and $73.53 \mathrm{kyr}$ in the Pearl River basin, respectively (Table 5 ).

To get a more detailed picture of the mutational pattern for population expansion of $N$. taihuensis within the Yangze River basin and the Huai River basin, GENETREE [44] was used to construct a gene tree for determining the distribution of mutation time. To make the sequence data suitable for the infinite-sites model, four haplotypes (H06, H07, H10, and H13) were excluded in this analysis. It is worth to note that the possible removal of data can have important effects on inference, and can lead to unusual conclusions [44], but the results from this procedure can provide a rough profile for the distribution of mutations. As shown in Figure. 6, it was evident that the vast majority of mutations occurred near the tips of the gene tree, with $61.54 \%$ mutations occurring within $15.6 \mathrm{kyr}$ in the Yangze River basin and $66.67 \%$ mutations occurring within $16.2 \mathrm{kyr}$ in the Huai River basin.

\section{Discussion}

\section{Population Genetic Structure and Phylogeography}

Our results revealed low nucleotide diversity $(\pi=0.0022$ $\pm 0.0001)$ and medium/high haplotype diversity $(h=$ $0.713 \pm 0.022$ ) in N. taihuensis (Table 1), which could reflect a recent expansion or a short evolutionary history of the population [1,45-47]. This scenario was also supported by the absence of deep branching among haplotypes in the genealogical tree and the "star-like" shaped network (Figure. 2 and Figure. 3) as well as NCA and demographic history analysis (Table 5).

Phylogenetic inference based on unrooted ML tree revealed that there were no distinct clades with high bootstrap support $(<60 \%)$ and individuals from three basins did not partition into distinct clades (Figure. 2), which indicated no geographical structure among haplotypes. The statistical parsimony network displayed a "star-like" shape with $\mathrm{H} 36$ being the most probable ancestral haplotype (outgroup weight: 0.2941) (Figure. 3), which also revealed a lack of geographical structure.

Beyond the prediction that vicariance among basins should play an important role in shaping population genetic structure, the results of AMOVA showed that the contemporary drainage structure served as a poor model in explaining the high levels of genetic differentiation, with only $8.43 \%$ variance among basins, it was suggested that there must be other factors shaping the genetic structure of $N$. taihuensis. Our results were in contrast to the 'Stream Hierarchy Model' [48], which showed that the distribution of genetic variation would follow different basins. Similar results were found in many studies of freshwater fish species $[5,9,49,50]$, including Opsariichthys bidens (Teleostei, Cyprinidae) conducted in the Pearl River and the Yangze River in China [8]. However, some researchers $[10,11,16]$ have reported population genetic structure in some freshwater fish species being analogous to our study, and these provided evidence that the contemporary drainage structure did not coincide with the genetic relationships among populations, or that the instream barriers and complex population histories played an important role in the determination of the population genetic structure.

Pair-wise comparisons between $\Phi_{S T}$ and AMOVA analysis confirmed the existence of some degree of restricted gene flow, which could be one of the important factors determining the genetic structure among populations of $N$. taihuensis. However, the Mantel test indicated no significant relationship between genetic differentiation and geographic distance among populations. The discrepancy between these results indicated that the pattern of genetic differentiation for $N$. taihuensis was complex and could not be interpreted simply using the IBD model. 

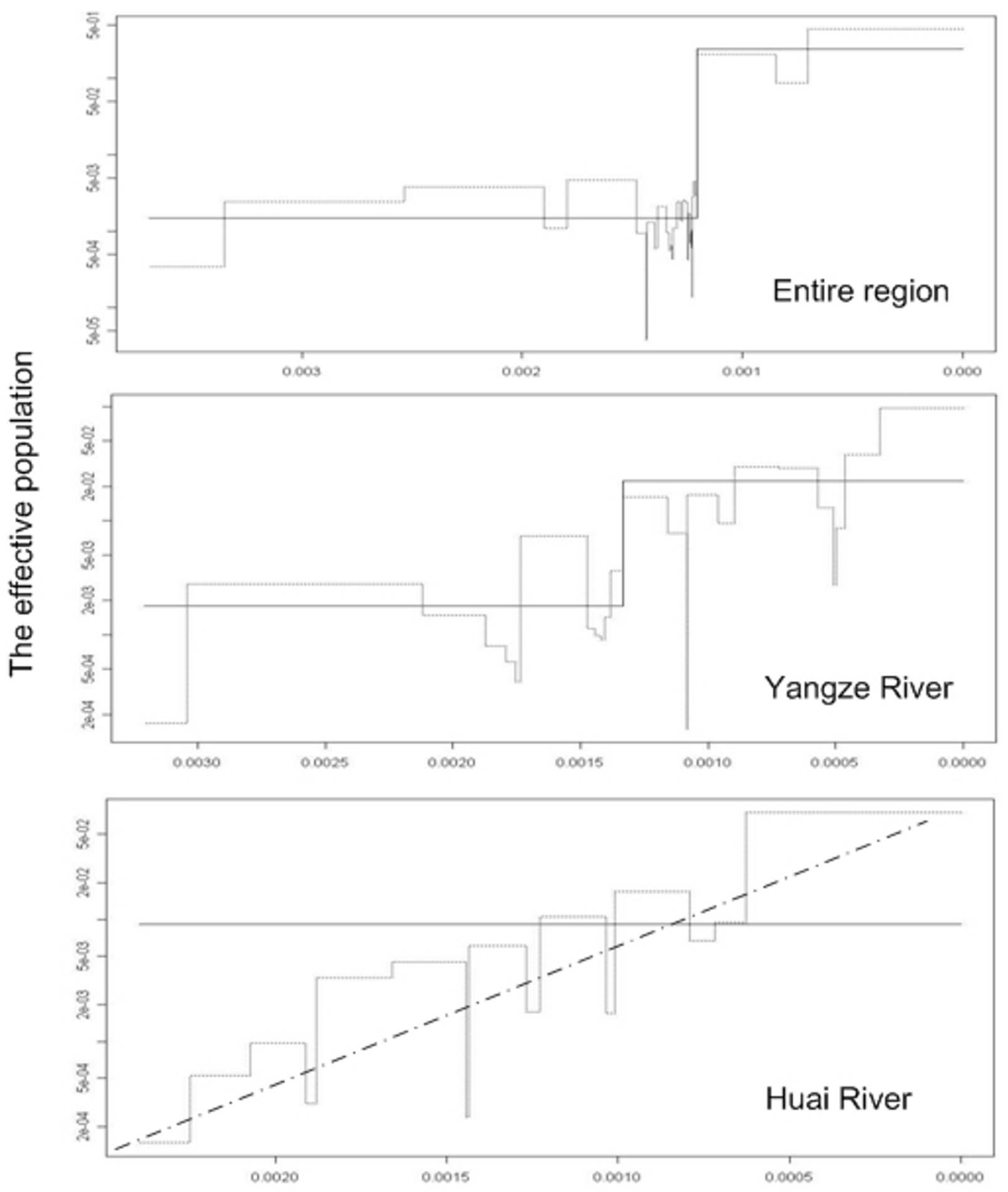

Time of mutations per site before present

Figure 4

Skyline plots of changes in effective population size on time. The $x$ axis is time of mutations per site before present; the $y$ axis is the effective population size equal to $N_{e} \mu$. Classic skyline was shown as thin line, generalized skyline as thick line, and dot line as the expected demographic history. 


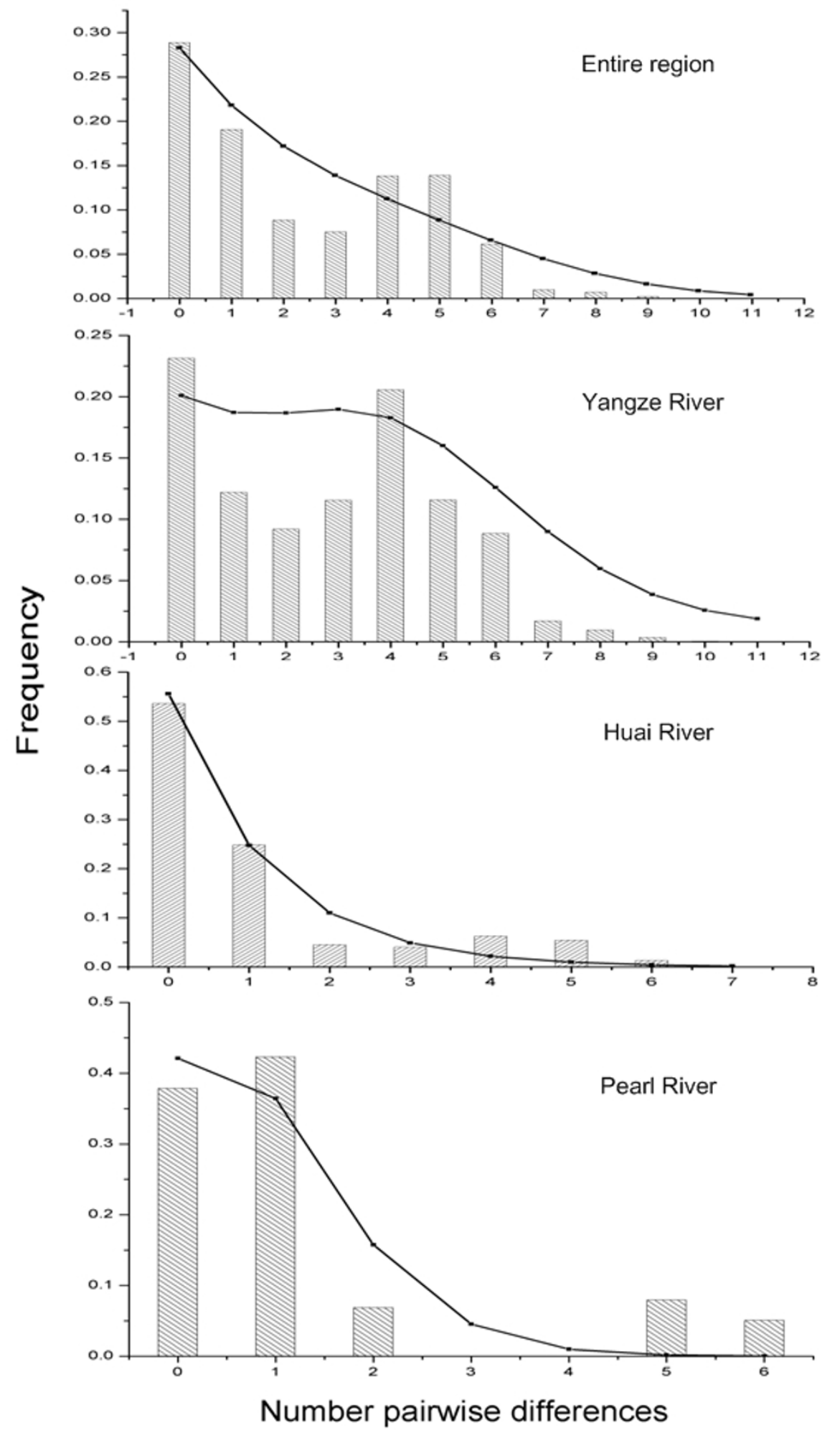

Figure 5

Observed and expected mismatch distributions showing the frequencies of pairwise differences. The observed distributions (bars) are compared for their goodness-of-fit to a Poisson distribution under a model of sudden expansion illustrated by the overlaid curve (black dots and solid lines). $X$-axis: number of pair-wise differences, $Y$-axis: frequency. 


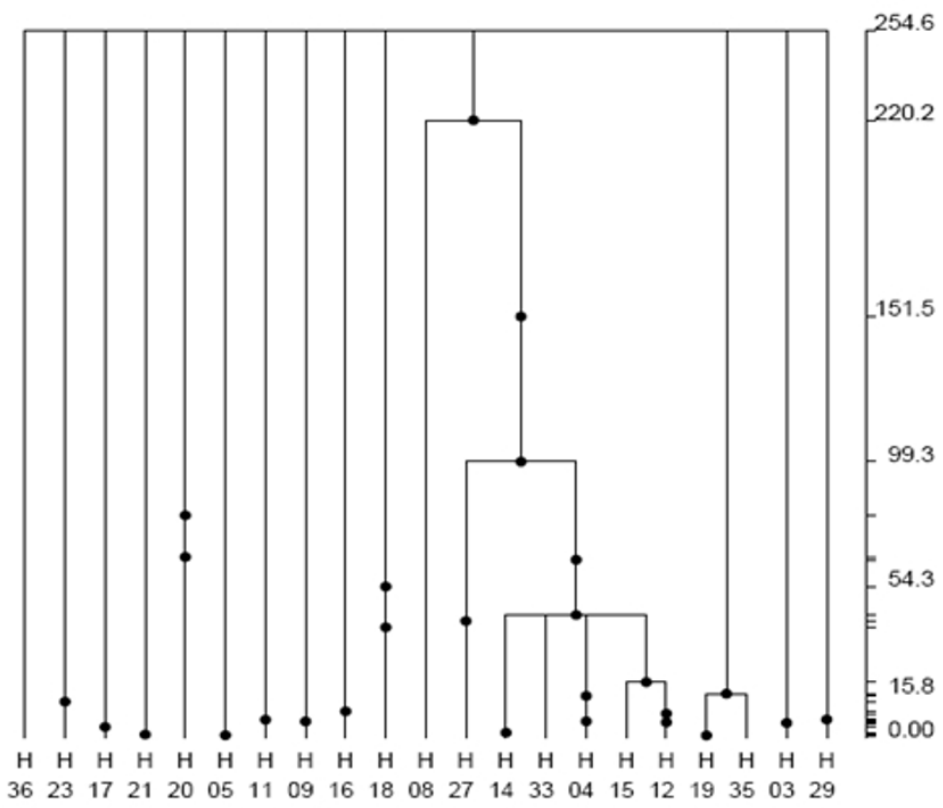

The Yangze River basin

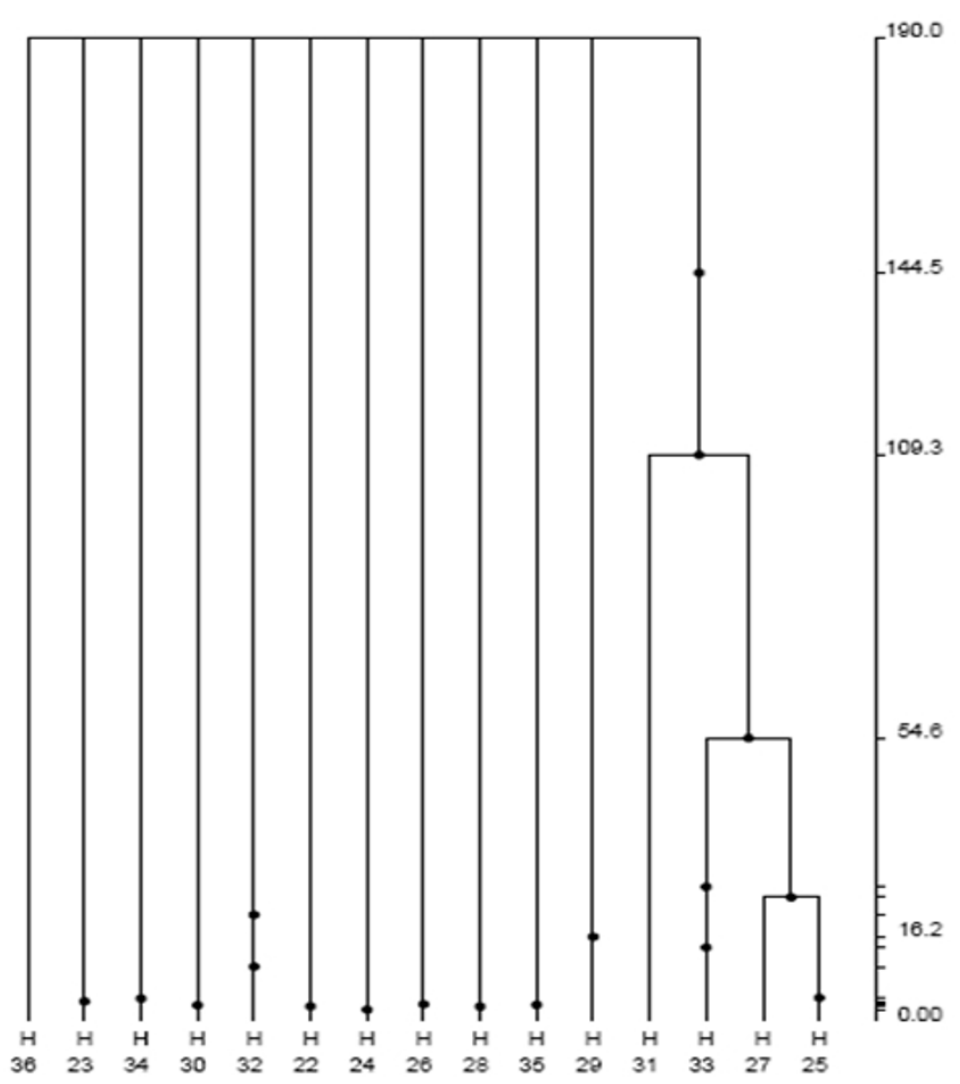

The Huai River basin

Figure 6

Gene tree of the $\mathbf{N}$. taihuensis mitochondrial cytb gene. The tree is based on $1,000,000$ coalescent simulations. The absolute time scale on the right shows the TMRCA (kyr) in generations using a mutation rate of $1 \% \times 10^{-6}$ per year. The tree shows the ancestral distribution of mutations and events (TMRCA, recent rapid expansion) in the population history. 
In contrast, NCA analysis revealed that multiple unrelated long-distance founding events could be important in determining the patterns of genetic diversity. In NCA, the large $D n$ and small $D c$ suggests long distance dispersal [16]. The NCA inferences for widespread clade 1-6, including the most probable ancestral haplotype H36 with a significantly small $D c$ and large $D n$, were indicative of range expansion and long-distance colonization (and/ or past fragmentation) [51]. The observed population relationships agreed with the population structure predicted by normal dispersal models of recently expanding populations, with a portion of individuals migrating beyond neighbouring demes because of rare long-distance migrants founding pocket populations under this dispersal scenario [16]. Also, theoretical study has proven that even though no effectively restricting gene flow exists under these conditions, the effects on these founderevents can persist for thousands of generations, which results in higher levels of divergence within than between rivers [4]. In addition, it was also suggested that historical basin rearrangements might form the analogous population genetic structure mentioned above $[10,16]$. Although a strong uplifting of the Tibetan plateau occurred during the Pleistocene in southwest China [31], there is no evidence to indicate that large-scale river rearrangement occurred after the Pliocene in our study area [32]. It may imply that historical basin rearrangements are not critical in determining the current population genetic structure of this species. Accordingly, we suggested that the current complex population genetic structure of this species was mainly constituted by multiple unrelated founding events (long-distance colonization) of dispersal, and also affected by contiguous population expansion and some degree of restricted gene flow.

\section{Demographic history}

Statistical analysis of sequences was originally developed to test selective neutrality of mutations and has recently been used to test for population expansion. Demographic events are also commonly analyzed by using the distribution of pair-wise differences or mismatch distributions of non-recombining DNA sequence such as mtDNA $[52,53]$. Comparative studies on the test power of various statistics suggested the superiority of $F s$ and $R_{2}$ over other statistics $[40,41]$. The power of these tests also depends on sample size, and the $R_{2}$ test is more powerful for a small sample while $F s$ is more powerful for a large sample [41]. In this study, Fs tests were significant for the entire region, Yangze River basin and Huai River basin. However, $R_{2}$ tests were significant for the entire region and Huai River basin, but not significant for Yangze River basin (Table 5). The different results for population expansion in this study may reflect the differences in sample size requirements of the tests as well as source information.
Mismatch distribution analysis was a common method to infer population demography; however, some of inferences of the mismatch analysis were not consistent with the results of the other indices in this study (Table 5). Besides a relative lower statistical power of demography analysis [41], other factors might also induce such scenario. First, the single stepwise expansion model in mismatch analysis might be inadequate for some populations [54], and the use of an incorrect demographic model can also lead to biased and invalid estimates of demographic history and other evolutionary parameters [55]. As the case for Huai River basin in this study, the skyline plot provided evidence that the exponential growth model could be more realistic than that of stepwise expansion (Figure 4). Second, mismatch analysis needed a pair of genes being chosen at random from the population. In populations having gone through a recent and still large expansion, the internal branches should be very short due to the star-like structure of the tree, and a very few mutations would accumulate on those branches [40,52]. In this case, pairs drawn from the sample would be not independent due to the shared portions of their genealogy [56]. In this study, both unrooted ML tree and the statistical parsimony network displayed "star-like" shape with no deep branching among halotypes (Figure 2, Figure 3). So the inadequate information inferred from mismatch analysis might attribute to the sign in the data set being swamped by non-independence in this study. Moreover, although the unrooted ML tree indicated that there were no distinct haplotype groups with high bootstrap support, the results of our phylogeographic analysis revealed that there were high levels of genetic differentiation among populations, and that the genetic pattern of this species was mainly constituted by multiple unrelated founding events. So cases of founder events not containing all genetic types in some regions might be unavoidable, and could severely affect the shape of the mismatch distribution. Finally, other factors such as high frequency of the ancestral haplotypes, population substructure, or inbreeding could also affect the shape of the mismatch distribution, but to an extent these effects had not been quantified [56].

However, the methods of mismatch distribution analysis and neutrality test did not make full use of the data [57]. The coalescent-based method, by incorporating information from the genealogical tree structure of DNA sequences, used more information in the data and seemed to be more adequate to estimate demographic growth $[43,57,58]$. In Yangze River and Huai River basin, three different coalescent-based methods, the skyline plot $[38,39]$, the estimate of population growth rate $(g)$ using FLUCTUATE 1.4 [43] and the distribution of mutations conducted by GENETREE [44], which provided the similar information of population expansion in these regions, 
suggested that the superiority of the coalescent-based method. In conclusion, despite of some inconsistency in these results, it was evident that the combined demographic analysis could confirm population expansion in Yangze River and Huai River basin, while a relative constant population size in Pearl River basin.

During the last glacial maximum (LGM, about $18 \mathrm{kyr}$ ago), with sea levels lowered (120-140 m below present sea level) [12], the present distribution range of $N$. taihuensis was almost completely exposed and eradicated, and this species should have been severely impacted by the past glaciations. Our estimate of TMRCA in the Pearl River and the Huai River basin, and the population expansion time for $N$. taihuensis in the Yangze River basin were much older than that of LGM. It was difficult to link the population demographic history to any particular Pleistocene paleo-climatic event. However, the gene tree (Figure. 6) provided evidence that the Pleistocene ice ages had a great effect on the demographic history of this species. That the vast majority of mutations occurred near the tips of the gene tree suggests that population expansion events mainly occurred after LGM. Therefore, we proposed that in the Yangze River basin and the Huai River basin, the N. taihuensis should have been the most severely impacted by the past glaciations, surviving in some refugium, and then post-glacial colonizations and population expansions occurred with the climate warming and sea levels uplifting after the late Quaternary (especially the LGM) [59]. Further, three near-coastal populations (the Taihu lake population and the Chaohu population in the Yangze River basin, the Hongzehu Lake population in the Huai River basin) contained higher numbers of haplotypes, haplotype diversity $(h)$ and nucleotide diversity $(\pi)$ (Table 1 ), suggesting that a glacial refugium could exist near the estuaries. However, N. taihuensis has been exposed to pollution and habitat destruction for decades; its population size has decreased drastically in out-flowing rivers and estuaries of these basins under study $[24,25]$. No sample from these locations could be collected to detect the probable glacial refugium. Further studies should be conducted in future. In addition, it is worthy to note that many attached lakes formed in these areas with sea levels uplifting after the LGM. For example, Chaohu Lake and Taihu Lake in the Yangze River basin shaped about 12 and $2.6 \mathrm{kyr}$ ago, respectively, and Hongzehu lake and Weishanhu lake in the Huai River basin was shaped about 1.4 and $0.6 \mathrm{kyr}$ ago, respectively [60]. This indicated that the formation of appropriate habitations facilitated historical population expansions. This inference was compatible with the "r-strategy" characteristic of $N$. taihuensis with high relative fertility and a shorter generation time [29], which also suggests its population size could be severely affected by climate and habitation. Thus, it is not surprising that $N$. taihuensis has maintained a relatively constant population size in the Pearl River basin, because this area is a subtropical zone, with average $2-3^{\circ} \mathrm{C}$ higher than in the Yangze River basin or the Huai River basin during the Pleistocene [61]. There was no large-scale creation of appropriate habitations (attached lakes) after the LGM in this area.

\section{Implications for Conservation}

The Salangid, Neosalanx taihuensis, is one of the most important commercial species in this family. The dry or frozen salangids are good materials in Chinese food, and they are also exported to Japan and other southern-east Asia countries. But, it has to be noticed that the population size of $N$. taihuensis and its fishing yield have decreased rapidly in recent years $[24,25]$. For example, the yield of Salangids per year in Poyanghu lake decreased from $6 \times 10^{5} \mathrm{~kg}$ in $1960 \mathrm{~s}$ to $10^{4} \mathrm{~kg}$ in 1987 [62], and the fishery production of $N$. taihuensis was completely collapsed in Poyanghu lake thereafter [63]. The yield of Salangids per year in the Yellow River has also decreased since 1987 , and the lowest yield per year less than $10^{3} \mathrm{~kg}$ occurred in 1990 [29]. According to our investigation being from 2004 to 2005 and the information from the local fishery management offices, both adults and juveniles are now rarely found in the Yellow River. Some authors thought that over-fishing was a serious problem [64], but You et al. suggested that over-fishing was not the most important threat to this species [65]. On the other hand, the water pollution should be also the one of the most serious threat to $N$. taihuensis $[25,63,66]$. The environment of $N$. taihuensis has been polluted because of the waste water from urban, industry and agriculture [25]. Finally, the threat to $N$. taihuensis is also from the habitat fragmentation. Since mid 1950s, the aquatic networks have been fragmented dramatically with the construction of dykes and floodgates across the river-lake connections $[60,66]$. Most of the lakes in the mid-lower reaches lost their connection with the main river watercourse by the mid 1980s [60]. Consequently, most of the small lakes nearly disappeared and the mid-large lakes shrank considerably resulting in unsuitable habitat for this species $[66,67]$. Up to the present, no specific protect action has been taken for $N$. taihuensis, so it is urgent to make an effective plan to protect this economically important species.

The study on population structure and its phylogeoraphic pattern could provide particularly information for us to more broadly consider conservation options and more accurately assign appropriate fishery management [68]. According to the model proposed by Moritz [69], Evolutionary Significant Units (ESUs) are designated on the basis of reciprocal monophyly at mitochondrial markers. In the present study, phylogenetic inference based on ML and NCA methods revealed that it was no geographical 
structure among haplotypes in $N$. taihuensis, suggesting that there was not a genetically distinct and independent population that could be considered as an ESU. However, AMOVA analysis indicated that significant genetic variance resulted from genetic differences among populations and within basins. In addition, based on low vagility, geographic isolation among most populations and rapidly population decline over the recent decades for this species $[24,25,63]$, we proposed that all populations should be managed and conserved separately. Moreover, special attention must be paid on habitat protection and pollution control because this species is susceptive to appropriate habitat change.

\section{Conclusion}

Our results showed that this species presented a very random genetic pattern and was not compatible with the present hydrological structure. This genetic pattern might be formed mainly by multiple unrelated long distance founding events, combining with population expansion and the instream barriers restricting gene flow. Demographic analysis revealed that the populations in the Pearl River basin (TMRCA approximately 73.53 kyr) has kept a relatively constant population size of $N$. taihuensis, but populations in the Yangze River basin and the Huai River basin expanded about 221.9 and 190.0 kyr ago, respectively, with the majority of mutations occurring after the LGM. We concluded that the more favourable climate and the formation of appropriate large-scale habitations facilitated this expansion. We suggested that it was necessary to develop a suitable management plan for N. taihuensis based on our results.

\section{Methods \\ Sample Collection}

We collected a total of 354 individuals of $N$. taihuensis from 13 populations in the Pearl River, Yangtze River, and Huai River basins from March in 2004 to September in 2005, 44 came from two populations of the Pearl River basin in 2005 (P1-P2), 196 from seven populations of the Yangtze River basin in 2004 (Y1-Y7), and 114 from four populations of the Huai River basin in 2005 (H1H4) (Figure. 1 and Table 1). To eliminate the possibility that these samples came from the related individuals (schools of fishes), we selected many patches from one location and resampled 2-4 times in same population. All samples (whole fish) were stored in $95 \%$ ethanol.

\section{DNA extraction, PCR amplification and Sequencing}

Total DNA was extracted from the muscle tissue using standard phenol/chloroform procedures [70] or following the method of Asahida et al. [71]. PCR was performed according to the method of Zhang et al. [30]. 1141 base pairs (bp) of $c y t b$ DNA were amplified using the primers L14321 (5'-CAGTGACTTCAAAAACCACCG-3') and
L15634 (5'-CTTAGCTTTGGGAGTTAAGGGT-3') in a $50 \mu \mathrm{l}$ reaction volume mixture containing $25 \mu \mathrm{l}$ Premix Taq (1.25 U EX Taq polymerase, $0.4 \mathrm{mM}$ of each dNTP Mixture, $4 \mathrm{mM} \mathrm{Mg2+;} \mathrm{TaKaRa,} \mathrm{Tokyo,} \mathrm{Japan),} 1.0 \mu \mathrm{M}$ of each primer, approximately 50-100 ng total genomic DNA template and 18-22 $\mu \mathrm{l}$ of sterile distilled water. A PE 9700 Thermal Cycler (Applied Biosystems) was used for the following cycles: pre-denaturation at $94^{\circ} \mathrm{C}$ for $5 \mathrm{~min} ; 30$ cycles of denaturation at $94^{\circ} \mathrm{C}$ for $30 \mathrm{~s}$, annealing at $54^{\circ} \mathrm{C}$ for $45 \mathrm{~s}$, and extension at $72^{\circ} \mathrm{C}$ for $1 \mathrm{~min} 10 \mathrm{~s}$, plus a final extension at $72^{\circ} \mathrm{C}$ for $10 \mathrm{~min}$. Purified PCR products were directly sequenced using primers L14321 and L15634 from both ends using the Big Dye Terminator Sequencing Kit (Perkin-Elmer, Norwalk, CT) in a semi-automated DNA analyzer (3700; Applied Biosystems). To avoid the errors in amplification and sequencing, all singletons among polymorphism sites were verified by an additional amplification and sequencing. Sequences were aligned using the Clustal X program [72] and rechecked against the inferred reading frame for the corresponding protein. Haplotypes were identified using Clustal $\mathrm{X}$, and the $c y t b$ haplotype sequences of $N$. taihuensis were deposited in GenBank (EU376454-EU376489).

\section{Data Analysis}

Genetic Diversity and Population Structure

In order to test whether there is recombination within $c y t$ $b$ gene, linkage disequilibrium (LD) test was conducted using DnaSP 4.10 [73] and the average degree of LD, or non-random association between nucleotide variants at different polymorphic sites was tested using $\mathrm{ZZ}$ statistics [74], which could be used for detecting intragenic recombination with the null hypothesis no recombination. Also, neutrality test for $c y t b$ was conducted in MEGA4.0 [75] to check selection by Z-test using the null hypothesis H0: $d_{N}=d_{S}[76,77]$, where $d_{S}$ and $d_{N}$ is the average number of synonymous substitutions per synonymous site and the average number of nonsynonymous substitutions per nonsynonymous site, respectively.

Genetic diversity was measured for all samples and for each basin grouping using haplotype diversity $(h)$ and nucleotide diversity $(\pi)$ [78]. Values for the numbers of haplotypes $(H)$, polymorphic sites $(S)$ and the mean numbers of pair-wise differences among sequences $(K)$ were also estimated. These diversity indices were computed using the software DnaSP 4.10 [73]. As unequal numbers of individuals varying from 13 to 34 per population in this study, Pearson's correlation tests were conducted to test values independence of the number of haplotypes $(H)$, haplotype diversity $(h)$ and nucleotide diversity $(\pi)$ against the number of individuals $(N)$. Population structure and genetic variation of $N$. taihuensis were characterized and compared with Arlequin version 3.11 [79]. Analysis of molecular variance (AMOVA) was 
used to asses the population configuration and the geographical pattern of population subdivision. In this study, populations were grouped according to different geographical hierarchies using $\Phi$-statistics [80]. Three hierarchical levels of subdivision were obtained: $\Phi_{C T}$, the degree of differentiation among all basins, $\Phi_{S C^{\prime}}$ the degree of differentiation among populations within basins, and $\Phi_{S T}$, the degree of differentiation among all populations. We tested whether the derived indices were significantly different from zero using a nonparametric permutation method (10,000 Permutations). Moreover, we estimated pair-wise genetics differentiation between populations with $\Phi_{S T}[80,81]$ that includes information on haplotypes frequency and information on haplotype sequences. Null hypothesis of genetic homogeneity was assessed by 10,000 replications and sequential Bonferroni corrections [82] for multiple comparisons were applied to all pairs comparisons. To verify the hypothesis of isolation-by-distance (IBD), correlation between pair-wise linearized $\Phi$ st/ (1- $\Phi$ st) and river distances $(\mathrm{Km})$ between populations were analyzed using the Mantel test [83] with 10,000 permutations. Mantel test were conducted for all 13 populations among basins, for 7 populations within Yangze River basin and for 4 populations within Huai River basin, respectively. The river distances between populations were determined based on river courses by AcrView 3.2, which was also used in NCA analysis.

\section{Phylogenetic and Phylogeographic Analysis}

For phylogenetic analysis, we constructed unrooted maximum-likelihood (ML) tree using the program PAUP* 4.0 [84]. The $\operatorname{TrN}+\mathrm{I}(\mathrm{I}=0.8148)$ model was selected as the best-fit model for analysis using MODELTEST 3.06 [85].

Intraspecific data typically consists of many similar sequences, some of which may be ancestral and its phylogenetic relationship are often more clearly and accurately represented by a network [86]. In the present study, we constructed a haplotype network based on statistical parsimony [87] using the program TCS version 1.18 [88]. A distance matrix for all pair-wise haplotype comparisons was constructed and the maximum number of mutational differences justified by the parsimony limit of 0.95 was estimated. The network first constructed haplotypes that differed by a single change and added increasingly more distant haplotypes until either all were included or the maximum number of mutational steps was reached [88]. To check the evolutionary mechanisms responsible for the spatial distribution of genetic variation, we conducted the Nested Clade Analysis (NCA). The resulting cladogram calculated by the TCS program was converted into a nested design using the nesting rules [89]. Reticulations, or equally parsimonious connections within the network, were resolved with two steps. First, alternative connections between haplotypes were broken following a series of rules based on coalescence theory [90]. Second, synapomorphies in the form of nonsynonymous substitutions in the cytb gene, a conservative class of substitutions, was used to resolve all cases in which assignment to a nested series was ambiguous [89]. The current and historic patterns of phylogenetic and geographic associations were statistically tested using NCA implemented in GeoDis 2.0 [91], under the null hypothesis of no geographic association among haplotypes using 10,000 permutations. The most suitable model explaining the historical geographical distribution was identified using the inference key [51]. It is appropriate to address the caveats of NCA analysis, the power of this method has been criticized for years [92-94], but Templeton defended NCA on both theoretical and empirical grounds, and insisted this method an extensively validated method for strong phylogeographic inference $[51,95]$. However, as no other better all-encompassing method can offer the ability to explore patterns relating to complex historical scenarios at present, the NCA method can still provide useful complementary information for phylogeographical analysis [96].

\section{Demographic Analysis}

To detect mechanisms responsible for observed mtDNA patterns on various spatial and time scales, we developed different data analysis methods. Due to the limits and pitfalls of each method, the combined results might provide the best approximation of the population structure and history.

First, changes over time in nonparametric estimates of the effective population size of $N$. taihuensis were evaluated with the skyline plots [38,39] using R 2.6.1 [97]. This method can provide a rough profile of population demographic fluctuation, and can be used as a model selection tool. The classic skyline plot typically produces 'noisy' plots that display the stochastic variability inherent in the coalescent process. While using the Akaike Information Criterion [98], the generalized skyline plot could reduce this noise, and thus produce smoother estimated population size plots [38]. As the power of skyline plots depends on the numbers of variable nucleotide sites $[38,55]$, we conducted skyline analysis for the entire region, the Yangtze River basin and the Huai River basin with exception of the Pearl River basin. Second, for the entire region and for each basin, we examined the observed distribution of pair-wise differences between sequences (mismatch distribution) [53]. Theoretical studies show that mismatch distributions are usually ragged or multimodal for populations at stationary demographic equilibrium, but are typically smoother or unimodal for populations that have recently undergone a demographic expansion [53]. Occasionally, a pronounced rate of heterogeneity is reported even among closely related lineages [59], so the pair-wise relative rate test (pRRT) implemented in HyPhy 
[99] was used to estimate and verify molecular clock constancy at the intraspecific level based on 1141 bp of 36 haplotypes and P. chinensis (DQ191115) [30] before performing the mismatch distribution analysis. One haplotype (H31) was identified to evolve at a significantly different pace from the others. After removing this haplotype (H31), no other violation of the molecular clock constancy was found, so the other 35 haplotypes were used for further analysis. Mismatch analysis was conducted using Arlequin 3.11 [79] under a model of population expansion. The overall validity of the estimated demographic model was evaluated by the tests of raggedness index (Hri) [100] and the sum of squared differences (SSD) [101]. Significance of Hri and SSD were assessed by parametric bootstraps (10,000 replicates), and the significant value was taken as evidence for departure from the estimated demographic model of sudden population expansion. Third, Fu and Li's $D^{*}$ [42], Fu's Fs [40] and Ramos-Onsins and Rozas's $R_{2}$ [41] tests for mutation/drift equilibrium were performed in DnaSP 4.10 [73] and Arlequin 3.11 [79] with 10,000 simulations. Although these methods are commonly used to test the selective neutrality of genetic markers, these estimators are also sensitive to demographic processes such as recent population expansion or bottleneck. Because we were interested in discriminating between demographic expansion and contraction, we chose two class test statistics, each with particular sensitivity to one demographic scenario. Fu and Li's $D^{*}$ is designed to detect an excess of old mutations, characteristic of a population that has experienced a historical reduction in effective population size $[42,102]$. In contrast, Fu's $F_{S}$ and $R_{2}$ are sensitive to an excess of recent mutations $[40,41]$. Finally, we used the coalescent-based method implemented in FLUCTUATE 1.4 [43] to estimate exponential growth rate $(g)$ for this species. All runs employed the following strategy: 10 short chains of 4,000 steps and five long chains of 400,000 steps, sampling every 20th step; random starting trees; empirical nucleotide frequencies; initial $g$ value of 0.0 , starting $\theta$-value from Watterson's estimate [103]; and a 2.424 transition/ transversion (ti/tv) rate determined from MEGA4 [75] under the Tamura-Nei model [104] using only ingroup sequences. Runs were repeated five times to ensure consistency of estimates. As the estimates of $g$ are biased upwards [43], a conservative approach in testing for significance was adopted in our study, with values larger than three standard deviations $(S D)$ of $g$ regarded as significant.

For stepwise expansion population, we used $\tau$ to calculate the expansion time. The mismatch distribution analysis provided a rough estimate of $\tau$, with the starting time of the expansion in units of $1 /(2 \mathrm{ut})$ generations, where $\mathrm{u}$ is the mutation rate per locus per generation. The relationship with the absolute time in years $(\mathrm{t})$, is $\mathrm{t}=\tau / 2 \mathrm{uT}$. The value of T is generation time ( 1 year for $N$. taihuensis), and the value of $\mathrm{u}$ is derived from $\mathrm{u}=\mu \mathrm{k}$, where $\mu$ is the mutation rate per nucleotide per generation, and $\mathrm{k}$ is the number of nucleotides in the sequence. For other populations, however, we used GENETREE [44] to estimate the time to the most recent common ancestor (TMRCA). GENETREE is based on a coalescent method to simulate gene trees conditional on their topology, which can be used to determine the distribution of TMRCA. In present study, the most probable ancestral haplotype was analyzed by TCS program, and the TMRCA for a constant population was calculated in GENETREE by first finding the maximum-likelihood estimate [105] of $\theta$ following the method of Joy et al. [106]. Each run was repeated three times with a different starting seed number and 1,000,000 coalescent simulations. To get a more detailed picture of the mutational pattern from population expansion, GENETREE was also used to construct a gene tree to determine the distribution of each mutation for $N$. taihuensis.

Since there is no fossil record for N. taihuensis to analyze their cartilage character, the genetic time clock is difficult to calibrate. However, it has been convincingly shown that most groups of fish have slower evolutionary rates compared with those of other species, for example primates [35]. A calibration rate of $0.8-1 \%$ per Myr per generation has been accepted for mitochondrial proteincoding genes in Salmoniformes or Osmeriformes in many studies $[70,107,108]$. For convenience, we used the mutation rate $\mu=1 \%$ in this study.

\section{Abbreviations}

AMOVA: Analysis of molecular variance; ML: maximum likelihood; NCA: nested clade analysis; IBD: isolation by distance; LGM: last glacial maximum; TMRCA: the most recent common ancestor.

\section{Authors' contributions}

LZ collected samples, isolated genomic DNA, and conducted the amplification and sequencing of the complete Cyt $b$ gene. He collected, analyzed and summarized the data, and drafted the manuscript; JZ collected some samples, contributed some sequencing and contributed some to its design; ZL participated in analysis and interpretation of data, and helped draft the manuscript; SMF revised the manuscript and conducted part of analysis; FW and MX revised the draft manuscript and gave their some comments; ML conceived the study and participated in its design and data interpretation, and preparing the manuscript. All authors read and approved the final manuscript. 


\section{Additional material}

\section{Additional file 1}

Nested clade analysis. Statistical analysis of the current and historic patterns of phylogenetic and geographic associations.

Click here for file

[http://www.biomedcentral.com/content/supplementary/14712148-8-201-S1.doc]

\section{Acknowledgements}

This project was supported by the National Basic Research Program of China (973 Program: 2007CB4 I I600) and the National Natural Science Foundation of China (No. 30570256). The authors would like to thank Dr. L.F. Zhu, and Dr. B. W. Zhang for their technical guidance and data analysis, L. Yan and Y. L. Hao for their laboratory assistance and useful ideas, and some staffs for their help in collecting samples. Special thanks are given to Prof. Y. Tao for polishing the English, Drs. T. Meng and D. W. Qi for providing geographic information and maps, and some anonymous reviewers for their constructive comments.

\section{References}

I. Avise JC: Phylogeography: The History and Formation of Species. USA: Harvard University Press; 2000.

2. Palumbi SR: Genetic divergence, reproductive isolation, and marine speciation. Annu Rev Ecol Syst 1994, 25:547-572.

3. Hewitt G: The genetic legacy of the Quaternary ice ages. Nature 2000, 405:907-913.

4. Kamal MI, Richard AN, Hewitt GM: Spatial patterns of genetic variation generated by different forms of dispersal during range expansion. Heredity 1996, 77:282-291.

5. Ward R, Woodwark M, Skibinski O: A comparison of genetic diversity levels in marine, freshwater and anadromous fishes. Journal of Fish Biology 1994, 44:213-232.

6. Gyllensten U: The genetic structure of fish: differences in the intraspecific distribution of biochemical genetic variation between marine, anadromous, and freshwater species. Journal of Fish Biology 1985, 26:691-699.

7. Hansen MM, Mensberg K-LD: Genetic differentiation and relationship between genetic and geographical distance in Danish sea trout (Salmo trutta L.) populations. Heredity 1998, 8I:493-508.

8. Perdices A, Sayanda D, Coelho MM: Mitochondrial diversity of Opsariichthys bidens (Teleostei, Cyprinidae) in three Chinese drainages. Mol Phylogenet Evol 2005, 37:920-927.

9. Xia YZ, Chen YY, Sheng Y: Phylogeographic Structure of Lenok (Brachymystax lenok Pallas) (Salmoninae, Salmonidae) Populations in Water Systems of Eastern China, Inferred from Mitochondrial DNA Sequences. Zoological Studies 2006, 45: $190-200$.

10. McGlashan DJ, Hughes JM: Reconciling patterns of genetic variation with stream structure, earth history and biology in the Australian freshwater fish Craterocephalus stercusmuscarum (Atherinidae). Molecular Ecology 2000, 9:1737-175I.

II. Currens K, Schreck C, Li WH: Allozyme and morphological divergence of rainbow trout (Oncorhynchus mykiss) above and below waterfalls in the Deschutes River, Oregon. Copeia 1990, 1990:730-746.

12. Lambeck K, Esat TM, Potter EK: Links between climate and sea levels for the past three million years. Nature 2002, 419:199-206.

13. Durand JD, Persat $\mathrm{H}$, Bouvet $\mathrm{Y}$ : Phylogeography and postglacial dispersion of the chub (Leuciscus cephalus) in Europe. Molecular Ecology 1999, 8:989-997.

14. Tsigenopoulos CS, Berrebi P: Molecular Phylogeny of North Mediterranean Freshwater Barbs (Genus Barbus: Cyprinidae) Inferred from Cytochrome b Sequences: Biogeographic and Systematic Implications. Molecular Phylogenetics and Evolution 2000, 14:165-179.

15. Avise JC, Arnold J, Ball RM, Bermingham E, Lamb T: Intraspecific Phylogeography: The Mitochondrial DNA Bridge Between Population Genetics and Systematics. Annual Review of Ecology and Systematics 1987, 18:489-522.

16. Cortey M, Pla C, Garcia-Marin JL: Historical biogeography of Mediterranean trout. Molecular Phylogenetics and Evolution 2004, 33:83I-844.

17. Fu C, Luo J, Wu J, Andres Lopez J, Zhong Y, Lei G, Chen J: Phylogenetic relationships of salangid fishes (Osmeridae, Salanginae) with comments on phylogenetic placement of the salangids based on mitochondrial DNA sequences. Molecular Phylogenetics and Evolution 2005, 35:76-84.

18. Waters J, Saruwatari T, Kobayashi T, Oohara I, McDowall R, Wallis GP: Phylogenetic placement of Retropinnid Fishes: data set incongruence can be reduced by using asymmetric character state transformation costs. Systematic Biology 2002, 5 I:432-449.

19. Zhang YL, Qiao XG: Study on phylogeny and zoogeography of fishes of the family Salangidae. Acta Zoologica Taiwanica 1994, 5:95-II5.

20. Nelson J: Fishes of the World. 3rd edition. New York: John Wiley \& Sons, Inc.; 1994.

21. Cheng QT, Zheng BS: Systematic Synopsis of Chinese Fishes. Beijing: Science Press; 1987.

22. Roberts T: Skeletal anatomy and classification of the neotenic Asian salmoniform superfamily Salangoidea (icefishes or noodlefishes). Proceedings of the California Academy of Science 1984, 43:179-220.

23. Bernatchez L, Wilson CC: Comparative phylogeography of Nearctic and Palearctic fishes. Molecular Ecology 1998, 7.

24. Wang ZS, Lu C, Hu HJ, Zhou Y, Xu CR, Lei GC: Freshwater icefishes (Salangidae) in the Yangtze River basin of China: Spatial distribution patterns and environmental determinants. Environmental Biology of Fishes 2005, 73:253.

25. Li SF: A study on biodiversity and its conservation of major fishes in the Yangtze River. Shanghai: Shanghai Scientific and Technical Publishers; 200I.

26. Knutsen $\mathrm{H}$, Jorde PE, Andre $\mathrm{C}$, Stenseth NC: Fine-scaled geographical population structuring in a highly mobile marine species: the Atlantic cod. Molecular Ecology 2003, I 2:385-394.

27. Regan C: Description of new fishes from Lake Candidius, Formosa, collected by Dr. A. Moltrecht. Annals and Magazine of Natural History Series 1908, 8:358-360.

28. Wakiya Y, Takahasi N: Study on fishes of the family Salangidae. Journal of the College of Agriculture, Imperial University of Tokyo 1937, 14:265-296.

29. Dou SZ, Chen DG: Taxonomy, biology and abundance of Icefishes Salangidae in the Yellow River estuary of the Bohai Sea, China. Journal of Fish Biology 1994, 45:737-748.

30. Zhang J, Li M, Xu MQ, Takita T, Wei FW: Molecular phylogeny of icefish Salangidae based on complete mtDNA cytochrome $b$ sequences, with comments on estuarine fish evolution. Biological Journal of the Linnean Society 2007, 9 I:325-340.

31. Kutzbach J, Ruddiman W, Prell W: Tectonic Uplift and Climate Change. New York 1997: I 49-I70.

32. Luo LX, Xing JM, Wang NQ, Shen YC, Ren ME, Zeng ZX, Zhu SD: The Physical Geography of China. Beijing: Science Press; 1981.

33. Huang $\times Q$, Su FC, Mei HA: Rivers in China. Beijing: Commercial Press; 1995

34. Myers GS: Salt-tolerance of fresh-water fish groups in relation to zoogeographical problems. Bijdr Dierk 1949, 28:3I5-322.

35. Cantatore P, Roberti M, Pesole G, Ludovico A, Milella F, Gadaleta MN, Saccone C: Evolutionary analysis of cytochrome b sequences in some Perciformes: evidence for a slower rate of evolution than in mammals. J Mol Evol 1994, 39:589-597.

36. Zhang D, Hewitt G: Nuclear integrations challenges for mitochondrial DNA markers. Trends of Ecology and Evolution 1996, I I:247-25I.

37. Castelloe J, Templeton AR: Root Probabilities for Intraspecific Gene Trees under Neutral Coalescent Theory. Molecular Phylogenetics and Evolution 1994, 3:102-113.

38. Strimmer K, Pybus OG: Exploring the Demographic History of DNA Sequences Using the Generalized Skyline Plot. Mol Biol Evol 200I, 18:2298-2305. 
39. Pybus OG, Rambaut A, Harvey PH: An Integrated Framework for the Inference of Viral Population History From Reconstructed Genealogies. Genetics 2000, I 55: | 429 - I 437.

40. Fu YX: Statistical Tests of Neutrality of Mutations Against Population Growth, Hitchhiking and Background Selection. Genetics 1997, 147:915-925.

41. Ramos-Onsins SE, Rozas J: Statistical Properties of New Neutrality Tests Against Population Growth. Mol Biol Evol 2002, 19:2092-2100

42. Fu YX, Li WH: Statistical Tests of Neutrality of Mutations. Genetics 1993, 133:693-709.

43. Kuhner MK, Yamato J, Felsenstein J: Maximum Likelihood Estimation of Population Growth Rates Based on the Coalescent. Genetics 1998, 149:429-434.

44. Bahlo M, Griffiths RC: Inference from Gene Trees in a Subdivided Population. Theoretical Population Biology 2000, 57:79-95.

45. Cook RM, Sinclair A, Stefansson G: Potential collapse of North Sea cod stocks. Nature 1997, 385:521-522.

46. Grant WAS, Bowen BW: Shallow population histories in deep evolutionary lineages of marine fishes: insights from sardines and anchovies and lessons for conservation. I Hered 1998, 89:4I5-426.

47. Frankham R: Relationship of genetic variation to population size in wildlife. Conservation Biology 1996, 10:1500-1508.

48. Meffe G, Vrijenhoek R: Conservation genetics in the management of desert fishes. Conservation Biology 1988, 2:157-169.

49. Hashiguchi $Y$, Kado T, Kimura S, Tachida H: Comparative phylogeography of two bitterlings, Tanakia lanceolata and T. limbata (Teleostei, Cyprinidae), in Kyushu and adjacent districts of western Japan, based on mitochondrial DNA analysis. Zoolog Sci 2006, 23:309-322.

50. Hynes R, Ferguson A, McCann M: Variation in mitochondrial DNA and post-glacial colonisation of north-west Europe by brown trout (Salmo trutta L.). Journal of Fish Biology 1996, 48:54-67.

5I. Templeton AR: Statistical phylogeography: methods of evaluating and minimizing inference errors. Molecular Ecology 2004 , 13:789-809.

52. Slatkin M, Hudson RR: Pairwise Comparisons of Mitochondria DNA Sequences in Stable and Exponentially Growing Populations. Genetics 1991, 1 29:555-562.

53. Rogers AR, Harpending $\mathrm{H}$ : Population growth makes waves in the distribution of pairwise genetic differences. Mol Biol Evol 1992, 9:552-569.

54. Polanski A, Kimmel M, Chakraborty R. Application of a timedependent coalescence process for inferring the history of population size changes from DNA sequence data. Proceedings of the National Academy of Sciences 1998, 95:5456-546I.

55. Drummond AJ, Rambaut A, Shapiro B, Pybus OG: Bayesian Coalescent Inference of Past Population Dynamics from Molecular Sequences. Mol Biol Evol 2005, 22: I I85-I I 92.

56. Schneider S, Excoffier L: Estimation of Past Demographic Parameters From the Distribution of Pairwise Differences When the Mutation Rates Vary Among Sites: Application to Human Mitochondrial DNA. Genetics 1999, 152:1079-1089.

57. Emerson BC, Paradis E, Thebaud C: Revealing the demographic histories of species using DNA sequences. Trends in Ecology \& Evolution 200I, 16:707.

58. Beheregaray LB, Ciofi C, Geist D, Gibbs JP, Caccone A, Powell JR: Genes Record a Prehistoric Volcano Eruption in the Galapagos. Science 2003, 302:75.

59. Liu JX, Gao TX, Yokogawa K, Zhang YP: Differential population structuring and demographic history of two closely related fish species, Japanese sea bass (Lateolabrax japonicus) and spotted sea bass (Lateolabrax maculatus) in Northwestern Pacific. Molecular Phylogenetics and Evolution 2006, 39:799.

60. Wang SM, Dou HS: Lakes in China. Beijing: Science Press; 1998.

61. Xia ZK: The Pleistocene Envioment. Beijing: Beijing University Press; 1997.

62. Chen $\mathrm{GH}$, Zhang B: study on the growth of salangid fishes in Poyang lake. JiangXi science 1991, 9:225-232.

63. Wang ZS, Fu CZ, Lui GC: Biodiversity of Chinese icefishes (Salangidae) and their consering strategies. Biodiversity Science 2002, 10:416-424.
64. Wang ZS, Lu C, Hu HJ, Xu CR, Lei GC: Dynamics of icefish (Salangidae) stocks in Nanyi Lake, eastern China: Degradation and overfishing. J Freshwater Ecol 2004, 19:27I-278.

65. You Y, You Q: A study on bioecological and economic effect of Neosalanx Taihuensis Chen in Taihu lake. Journal of Southwest Nationalities College 1999, 25:269-273.

66. Zeng XC: Fishery resources in the Yangtze River basin. Beijing: Marine Press; 1990.

67. Xie $P$, Chen $Y$ : Threats to biodiversity in Chinese inland waters. Ambio 1999, 28:674-68I.

68. Whiteley AR, Spruell P, Allendorf FW: Can common species provide valuable information for conservation? Molecular Ecology 2006, 15:2767-2786

69. Moritz C: Applications of mitochondrial DNA analysis in conservation: a critical review. Molecular Ecology 1994, 3:40 I-4II.

70. Sheldon JM, Robert HD, Michael JS: Phylogeny of Pacific salmon and trout based on growth hormone type-2 and mitochondrial NADH dehydrogenase subunit 3 DNA sequences. Can J Fish Aquat Sci 1996, 53:1165-1176.

7I. Asahida T, Kobayashi T, Saito K, Nakayama I: Tissue. preservation and total DNA extraction from fish stored at ambient temperature using buffers containing high concentration of urea. Fisheries Science 1996, 62:727-730.

72. Thompson JD, Gibson TJ, Plewniak F, Jeanmougin F, Higgins DG: The CLUSTAL_ $X$ windows interface: flexible strategies for multiple sequence alignment aided by quality analysis tools. NuCl Acids Res 1997, 25:4876-4882.

73. Rozas J, Sanchez-DelBarrio JC, Messeguer X, Rozas R: DnaSP, DNA polymorphism analyses by the coalescent and other methods. Bioinformatics 2003, 19:2496-2497.

74. Rozas I, Gullaud M, Blandin G, Aguade M: DNA Variation at the rp49 Gene Region of Drosophila simulans: Evolutionary Inferences From an Unusual Haplotype Structure. Genetics 200I, I58: | |47-I I55.

75. Tamura K, Dudley J, Nei M, Kumar S: MEGA4: Molecular Evolutionary Genetics Analysis (MEGA) Software Version 4.0. Mol Biol Evol 2007, 24:1596-1599.

76. Nei M, Gojobori T: Simple methods for estimating the numbers of synonymous and nonsynonymous nucleotide substitutions. Mol Biol Evol 1986, 3:418-426.

77. Zhang J, Rosenberg HF, Nei M: Positive Darwinian selection after gene duplication in primate ribonuclease genes. PNAS 1998, 95:3708-37|3

78. Nei M: Molecular Evolutionary Genetics. New York: Columbia University Press; 1987.

79. Excoffier L, Laval LG, Schneider S: Arlequin ver. 3.0: An integrated software package for population genetics data analysis. Evolutionary Bioinformatics Online 2005, I:47-50.

80. Weir B, Cockerham C: Estimating F-statistic for the analysis of population structure. Evolution 1984, 38: I358-1370.

8I. Excoffier L, Smouse PE, Quattro JM: Analysis of Molecular Variance Inferred From Metric Distances Among DNA Haplotypes: Application to Human Mitochondrial DNA Restriction Data. Genetics 1992, I3 I:479-491.

82. Rice WR: Analyzing tables of statistical tests. Evolution 1989, 43:223-225.

83. Mantel N: The Detection of Disease Clustering and a Generalized Regression Approach. Cancer Res 1967, 27:209-220.

84. Swofford D: paup*: Phylogenetic Analysis Using Parsimony (*and Other Methods), Version 4.0b I0. Massachusetts: Sinauer As sociates, Sunderland; 2002.

85. Posada D, Crandall KA: MODELTEST: testing the model of DNA substitution. Bioinformatics 1998, 14:817-818.

86. Posada D, Crandall KA: Intraspecific gene genealogies: trees grafting into networks. Trends in Ecology \& Evolution 200I, 16:37-45

87. Templeton AR, Crandall KA, Sing CF: A Cladistic Analysis of Phenotypic Associations With Haplotypes Inferred From Restriction Endonuclease Mapping and DNA Sequence Data. III. Cladogram Estimation. Genetics 1992, 132:619-633.

88. Clement M, Posada D, Crandall KA: TCS: a computer program to estimate gene genealogies. Molecular Ecology 2000, 9:1657-1659.

89. Templeton AR, Sing CF: A cladistic analysis of phenotypic associations with haplotypes inferred from restriction endonu- 
clease mapping. IV. Nested analyses with cladogram uncertainty and recombination. Genetics 1993, 134:659-669.

90. Crandall KA, Templeton AR: Empirical tests of some predictions from coalescent theory with applications to intraspecific phylogeny reconstruction. Genetics 1993, 134:959-969.

91. Posada D, Crandall KA, Templeton AR: GeoDis: a program for the cladistic nested analysis of the geographical distribution of genetic haplotypes. Mol Ecol 2000, 9:487-488.

92. Knowles LL, Maddison WP: Statistical phylogeography. Molecular Ecology 2002, I I:2623-2635.

93. Petit RJ: On the falsifiability of the nested clade phylogeographic analysis method. Molecular Ecology 2008, 17:1404-| 404.

94. Panchal M, Beaumont MA: The automation and evaluation of nested clade phylogeographic analysis. Evolution 2007, 6 I: |466-| 480.

95. Templeton AR: Nested clade analysis: an extensively validated method for strong phylogeographic inference. Molecular Ecology 2008, 17:1877-1880.

96. Garrick RC, Dyer RJ, Beheregaray LB, Sunnucks P: Babies and bathwater: a comment on the premature obituary for nested clade phylogeographical analysis. Molecular Ecology 2008, I7:| $401-1403$.

97. Ihaka R, Gentleman R: R: A Language for Data Analysis and Graphics. Journal of Computational and Graphical Statistics 1996, 5:299-3।4.

98. Akaike $\mathrm{H}$ : A new look at the statistical model identification. IEEE Transactions on Automatic Control I 974, AC-19:716-723.

99. Pond SLK, Frost SDW, Muse SV: HyPhy: hypothesis testing using phylogenies. 2005, $21: 676-679$.

100. Harpending $\mathrm{H}$ : Signature of ancient population growth in a low-resolution mitochondrial DNA mismatch distribution. Hum Biol 1994, 66:59I-600.

101. Durka W, Bossdorf O, Prati D, Auge H: Molecular evidence for multiple introductions of garlic mustard (Alliaria petiolata, Brassicaceae) to North America. Molecular Ecology 2005, 14:1697-I706.

102. Fu YX: New Statistical Tests of Neutrality for DNA Samples From a Population. Genetics 1996, 143:557-570.

103. Watterson GA: On the number of segregating sites in genetical models without recombination. Theoretical Population Biology 1975, 7:256-276

104. Tamura K, Nei M: Estimation of the number of nucleotide substitutions in the control region of mitochondrial DNA in humans and chimpanzees. Mol Biol Evol 1993, 10:512-526.

105. Riley SPD, Pollinger JP, Sauvajot RM, York EC, Bromley C, Fuller TK, Wayne RK: A southern California freeway is a physical and social barrier to gene flow in carnivores. Molecular Ecology 2006, I5:|733-|74|

106. Joy DA, Feng $X, M u$ J, Furuya T, Chotivanich K, Krettli AU, Ho M, Wang A, White NJ, Suh E, Beerli P, Su XZ: Early Origin and Recent Expansion of Plasmodium falciparum. Science 2003, 300:318-32I.

107. Smith GR: Introgression in Fishes: Significance for paleontology, cladistics, and evolutionary rates. Systematic Biology 1992, 41:4I-57.

108. McCusker MR, Parkinson E, Taylor EB: Mitochondrial DNA variation in rainbow trout (Oncorhynchus mykiss) across its native range: testing biogeographical hypotheses and their relevance to conservation. Molecular Ecology 2000, 9:2089-2108.
Publish with Bio Med Central and every scientist can read your work free of charge

"BioMed Central will be the most significant development for disseminating the results of biomedical research in our lifetime. "

Sir Paul Nurse, Cancer Research UK

Your research papers will be:

- available free of charge to the entire biomedical community

- peer reviewed and published immediately upon acceptance

- cited in PubMed and archived on PubMed Central

- yours - you keep the copyright
BioMedcentral 